\title{
ANATOMIA DO XILEMA SECUNDÁRIO DE EUGENIA MANSOI O. BERG (MYRTACEAE) ${ }^{1}$
}

\author{
JOSE NEWTON CARDOSO MARCHIORI² SIDINEI RODRIGUES DOS SANTOS ${ }^{3}$
}

\section{RESUMO}

A anatomia da madeira de Eugenia mansoi O. Berg é descrita, com base em material do Rio Grande do Sul. Entre outros caracteres anatômicos, salientam-se: porosidade difusa, poros predominantemente ou exclusivamente solitários, placas de perfuração simples, pontoações intervasculares alternas e raios heterogêneos estreitos. Sob o ponto de vista taxonômico, são especialmente importantes: a ausência de ornamentações em pontoações, o parênquima axial difuso-em-agregados e em linhas tangenciais, e as fibras com pontoações areoladas.

Palavras-chave: Eugenia mansoi, Anatomia da Madeira, Myrtaceae.

\section{ABSTRACT}

[Wood anatomy of Eugenia mansoi O. Berg (Myrtaceae)].

The wood anatomy of Eugenia mansoi O. Berg is described, based on materials from Rio Grande do Sul state, Brazil. Diffuse porous wood, with predominantly or exclusively solitary vessels, simple perforation plates, alternate intervessel pits and narrow heterogeneous rays, were observed. The absence of vestured pits in vessel walls, the presence of diffuse-in-aggregates parenchyma cells, associated with tangential lines, and the presence of bordered pits on fibers, are specially important under the taxonomic point of view.

Key words: Eugenia mansoi, Wood Anatomy, Myrtaceae.

\section{INTRODUÇÃO}

O gênero Eugenia L. compreende mais de 500 espécies de árvores e arbustos, dispersas, em sua maioria, pelas regiões tropicais e subtropicais da América, Ásia e, mais raramente, da Austrália e África (Record \& Hess, 1949). De acordo com a concepção taxonômica mais atualizada, que inclui os gêneros Calycorectes e Hexachlamys, o gênero Eugenia inclui 31 espécies nativas no Rio Grande do Sul (Sobral, 2003).

1 Recebido para publicação em 14/11/2008 e aceito para publicação em 30/11/2008.

2 Engenheiro Florestal, Dr., Professor Titular do Departamento de Ciências Florestais, Universidade Federal de Santa Maria, Santa Maria, RS, Brasil. Bolsista de Produtividade em Pesquisa, CNPq - Brasil. balduinia@mail.ufsm.br

2 Biólogo, bolsista do $\mathrm{CNPq}$ - Brasil, doutorando do Programa de Pós-Graduação em Engenharia Florestal, Departamento de Ciências Florestais, Universidade Federal de Santa Maria, CEP 97105-900, Santa Maria, RS, Brasil.
Conhecida popularmente como pitangaamarga ou falsa-pitanga, Eugenia mansoi O. Berg é nativa em matas ciliares do Paraguai, Argentina, Uruguai e Brasil (Rotman, 2005), de São Paulo ao Rio Grande do Sul (Mattos, 1984). Para este Estado, Sobral (2003) refere coletas nas matas ciliares dos rios Ibicuí, Ijuí e Jacuí.

Árvore de pequeno porte (até $5 \mathrm{~m}$ ), Eugenia mansoi apresenta casca persistente, com pequenos sulcos. As folhas, simples, opostas, ovais (comprimento/largura $<2,5$ ), acuminadas e de margem inteira, são de consistência papirácea, concolores ou levemente discolores, apresentando o primeiro e segundo par de nervuras secundárias em ângulo de $45-55^{\circ}$, com relação à nervura principal (Santander \& González, 2007). A madeira, devido à pequena dimensão dos troncos, é utilizada apenas como lenha (Marchiori \& Sobral, 1997).

Ainda desconhecida sob o ponto de vista anatômico, a descrição do xilema secundário de Eugenia mansoi constitui o objetivo do presen- 
te trabalho, que visa a contribuir para o conhecimento estrutural das Mirtáceas nativas no Rio Grande do Sul.

\section{REVISÃO DE LITERATURA}

No tocante ao aspecto, propriedades e estrutura da madeira, a variação entre espécies de Eugenia mostra-se tão grande como a verificada entre diferentes gêneros da subfamília Myrtoideae (Record \& Hess, 1949).

Com relação aos caracteres anatômicos, a literatura dispõe de escassas informações, sendo raras as descrições pormenorizadas de espécies nativas. Para o conjunto do gênero, Metcalfe \& Chalk (1972) referem vasos muito numerosos e de diâmetro muito pequeno a médio, geralmente solitários ou então em múltiplos ocasionais até numerosos de 2-4 poros, providos, em algumas espécies, de espessamentos espiralados. O parênquima axial, inteiramente ou predominantemente apotraqueal, pode ser paratraqueal aliforme ou confluente em raras espécies. Os raios, de células procumbentes, eretas e quadradas, podem compor-se inteira ou predominantemente de células procumbentes (Metcalfe \& Chalk, 1972).

No parênquima axial de Eugenia, bem como das Mirtáceas em geral, são frequientes os cristais de oxalato de cálcio, em câmaras. Para algumas espécies é assinalada, por diversos autores, a presença de grãos de sílica no parênquima axial e/ou em células radiais, bem como de septos em fibras e de canais esquizógenos (Metcalfe \& Chalk, 1972). A presença de tiloses, por sua vez, é referida por Dadswell \& Eckersley (1935) para os vasos de algumas espécies de Eugenia, entre outros gêneros da família.

Para Eugenia involucrata DC., Marchiori (1984) refere elementos vasculares longos (365$582-843 \mu \mathrm{m})$, numerosos a muito numerosos (1420-28/ $\mathrm{mm}^{2}$ ) e com 38-53-73 $\mu \mathrm{m}$ de diâmetro, aspectos que concordam com a natureza higrófila da espécie. Para a identificação anatômica, o autor salienta, ainda, a presença de tênues espessamentos espiralados em vasos, de pontoações simples em fibras, a heterogeneidade do tecido radial, bem como os valores quantitativos de fibras, parênquima axial e raios.

Em estudo comparativo do lenho de Eugenia uniflora L. e E. cerasiflora Miq., Soffiatti \& Alfonso (1999) destacam a uniformidade estrutural de ambas as madeiras, distiguindo-as com base no parênquima axial e presença de cristais.

\section{MATERIAL E MÉTODOS}

O material estudado consiste de duas amostras de madeira, coletadas no município de São Vicente do Sul, Rio Grande do Sul. As amostras de madeira e exsicatas botânicas foram incorporadas à Xiloteca e Herbário do Departamento de Ciências Florestais da Universidade Federal de Santa Maria (HDCF), sob os números 2387 e 2391, respectivamente.

Para a descrição da madeira, foram preparadas lâminas de cortes anatômicos e de macerado. Do material lenhoso, foram extraídos três corpos de prova $(2 \times 1 \times 3 \mathrm{~cm})$ da parte mais externa do lenho, próxima ao câmbio, orientados para obtenção de cortes nos planos transversal, longitudinal radial e longitudinal tangencial. Um outro bloco foi também retirado, com vistas à maceração. O preparo de lâminas de cortes anatômicos seguiu a técnica padrão no Laboratório de Anatomia da Madeira da Universidade Federal do Paraná: as amostras de madeira foram amolecidas por fervura em água e seccionadas em micrótomo de deslizamento, regulado para a obtenção de cortes com espessura nominal de $20 \mu \mathrm{m}$. Estes, foram tingidos com acridina-vermelha, crisoidina e azul-de-astra (Dujardin, 1964), desidratados em série alcoólica-ascendente (30\%, 50\%, 70\%, 95\% e duas vezes em álcool absoluto), diafanizados em xilol e montados em lâminas permanentes, usando-se "Entellan" como meio de montagem. Para as lâminas de macerado, adotou-se o método de Jeffrey (Burger \& 
Richter, 1991) e coloração da pasta com safranina 1\%; a montagem de lâminas seguiu o anteriormente descrito, com a diferença de que as três primeiras etapas foram desenvolvidas sobre papel de filtro.

A descrição microscópica da madeira baseou-se nas recomendações do IAWA Committee (1989). No caso da percentagem dos tecidos foram realizadas 600 determinações ao acaso, usando-se contador de laboratório, conforme proposto por Marchiori (1980). A freqüência de poros $/ \mathrm{mm}^{2}$ foi obtida de forma indireta, a partir de um quadrado de área conhecida, superposto a fotomicrografias de seção transversal da madeira. As medições foram realizadas em microscópio Carl Zeiss, com ocular de escala graduada, no Laboratório de Anatomia da Madeira da Universidade Federal de Santa Maria. Nas características quantitativas, os números entre parênteses equivalem aos valores mínimos e máximos observados. $\mathrm{O}$ valor que acompanha a média é o desvio padrão. As fotomicrografias foram tomadas em microscópio Olympus CX40, equipado com câmera digital Olympus Camedia C3000.

\section{DESCRIÇÃO ANATÔMICA}

Madeira de porosidade difusa. Anéis de crescimento distintos, delimitados pelo achatamento radial das fibras e, menos freqüentemente, pela presença de estreita zona fibrosa mais escura no limite do anel de crescimento, ou pelo alinhamento tangencial de poros no lenho inicial (Figura $1 \mathrm{~A}, \mathrm{~B})$.

Vasos muito numerosos a extremamente numerosos, com média variando de 64 (HDCF 2391) a 221 (HDCF 2387) poros $/ \mathrm{mm}^{2}$, ocupando, respectivamente, 8,8 a $19 \%$ do volume médio da madeira. Conteúdo de coloração castanha ou avermelhada, escasso e de presença ocasional em vasos. Poros exclusiva ou predominantemente solitários e em múltiplos radiais curtos (2-4 poros), de seção poligonal, por vezes circular a oval, muito pequenos $(29,7 \pm 8,1$ (15 - 55) $\mu \mathrm{m})$, de paredes finas $(2,8 \pm 0,6(2,5-$
$5,0) \mu m$ ) e sem padrão definido de organização (Figura 1A,B). Elementos vasculares de comprimento médio $(592,4 \pm 120,6(380-860) \mu \mathrm{m})$, com placas de perfuração simples (Figura 1D), oblíquas, e apêndices geralmente em ambas as extremidades. Pontoações intervasculares alternas, não ornamentadas, circulares $(4,4 \pm 0,5(4,1$ - 5,1) $\mu \mathrm{m}$ ) e com abertura em fenda inclusa (Figura 1E). Pontoações raio-vasculares semelhantes às intervasculares, embora menores $(3,7 \pm$ $0,5(3,1-4,1) \mu \mathrm{m})$ e restritas às margens dos raios. Espessamentos espiralados, ausentes.

O parênquima axial, abundante, contrasta com o tecido fibroso; com freqüência de 16 (HDCF 2387) a 22 (HDCF 2391) \% do volume da madeira, dispõe-se em arranjo apotraqueal difuso-em-agregados e em linhas tangenciais estreitas (1 - 3 células de largura), por vezes reunidas em faixas contínuas (Figura 1A,B). Séries parenquimáticas geralmente com 8 (4 11) células, medindo 581,4 \pm 78,0 (375 - 740) $\mu \mathrm{m}$ de altura (Figura 1F). Séries cristalíferas abundantes, com até 12 cristais prismáticos solitários, em células normais ou subdivididas do parênquima axial, maiores do que as adjacentes (Figura 1G).

Raios muito numerosos ( $23 \pm 2,4$ raios $/ \mathrm{mm})$, ocupando $20,4 \pm 3,7 \%$ do volume da madeira. Raios heterocelulares (Figura 1C), compostos de células procumbentes na parte multisseriada, e 1-16 (mais comumente 3-8) fileiras marginais de células quadradas e, principalmente, eretas. Raios estreitos, com 1-2 (raro 3) células de largura (Figura 1F,G). Raios multisseriados com 5 24 (mais comumente $7-13$ ) células e $365 \pm 159$ (120 - 800) $\mu \mathrm{m}$ de altura; a parte multisseriada é geralmente mais curta do que as margens unisseriadas. Raios unisseriados com 256,8 \pm

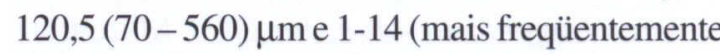
2-6) células de altura. Raios axialmente fusionados, freqüentes. Inclusões minerais, células envolventes e células perfuradas, ausentes; conteúdo de coloração escura, escasso.

Fibras com pontoações distintamente areoladas nas paredes radiais e tangenciais, com 
aberturas cruzadas (Figura 1G). Tecido fibroso representando 47,3 $\pm 4,3 \%$ do volume da madeira. Fibras de comprimento médio $(989,6 \pm$ $155,4(660$ - 1270) $\mu \mathrm{m})$, com 14,9 $\pm 2,7(10-$ $22,5) \mu \mathrm{m}$ de largura, e paredes finas a espessas, por vezes muito espessas $(5,1 \pm 1,1(3,1-7,5)$ $\mu \mathrm{m})$. Fibras septadas, fibras gelatinosas e espessamentos espiralados, ausentes. Traqueídeos vasicêntricos, presentes.

Demais caracteres: Variantes cambiais, tubos laticíferos e taniníferos, canais intercelulares, máculas, células oleíferas ou mucilaginosas e estratificação, ausentes.

\section{ANÁLISE DA ESTRUTURA ANATÔMICA}

A estrutura anatômica de Eugenia mansoi reúne características típicas de Myrtaceae, segundo Record \& Hess (1949) e Vliet \& Baas (1984). É o caso da porosidade difusa, das placas de perfuração simples, das pontoações intervasculares alternas, do parênquima apotraqueal seriado, dos raios heterogêneos e estreitos, das fibras com pontoações areoladas, e dos traqueídeos vasicêntricos. Menos freqüente na referida família botânica (Vliet \& Baas, 1984), a presença de poros em múltiplos radiais está de acordo com o relacionado por Metcalfe \& Chalk (1972) para Eugenia spp. Poros solitários foram também observados por Marchiori (1984b), em estudo anatômico de Eugenia involucrata, e por Soffiatti \& Angyalossy-Alfonso (1999), para outras duas espécies do mesmo gênero. Cabe salientar, todavia, que na espécie em estudo observaram-se poros solitários apenas na amostra com menor freqüência do caráter (HDCF 2391), fato que limita o valor diagnóstico do mesmo.

Ainda com relação aos vasos, cabe destacar a ausência de ornamentações no pontoado intervascular, caráter freqüente no gênero em estudo (Marchiori, 1984b; Soffiatti \& Angyalossy-Alfonso, 1999) e em outros da família, investigados por Marchiori (1984a,c, 1987a,b, 1988, 1997, 1998).
Metcalfe \& Chalk (1972) reportam espessamentos espiralados para algumas espécies de Eugenia e Myrcengenia. A ausência do caráter em Eugenia mansoi, embora predominante na família, pode contribuir para separar esta espécie de outras afins, caso de $E$. involucrata (Marchiori, 1984b), provida de espessamentos espiralados tênues, bem como de Myrceugenia myrtoides (Marchiori, 1987b), M. glaucescens (Marchiori, 1988) e Campomanesia guazumaefolia (Marchiori, 1998).

Pouco freqüente na família, a presença de parênquima apotraqueal em linhas tangenciais mostra-se de valor diagnóstico (Wiedenbrug, 1948; Vliet \& Baas, 1984), servindo, por exemplo, para separar a espécie em estudo de $E$. involucrata, espécie que, de acordo com Marchiori (1984b), apresenta parênquima difuso. Soffiatti \& Angyalossy-Alfonso (1999) valeramse do mesmo caráter para separar outras duas espécies de Eugenia, demonstrando seu valor diagnóstico para o referido gênero botânico. A presença de séries cristalíferas no parênquima axial é aspecto freqüente na família, inclusive em espécies de Eugenia, como demonstram os estudos de Marchiori (1984) e Soffiatti \& Angyalossy-Alfonso (1999); a abundância do caráter, aliás, pode servir para a identificação de espécies, de acordo com as duas últimas autoras. Com relação às madeiras nativas investigadas por Marchiori e listadas na bibliografia, Myrciaria tenella, Calyptranthes concinna, Myrceugenia myrtoides, M. glaucescens e Campomanesia guazumaefolia não apresentam inclusões minerais na estrutura anatômica.

A estrutura radial é muito semelhante ao observado por Marchiori (1984b) e por Soffiatti \& Angyalossy-Alfonso (1999) para outras espécies do mesmo gênero, carecendo de importância sob o ponto de vista taxonômico. Em nível genérico, o caráter pode ser útil, como no caso de Campomanesia, gênero com raios mais largos, 

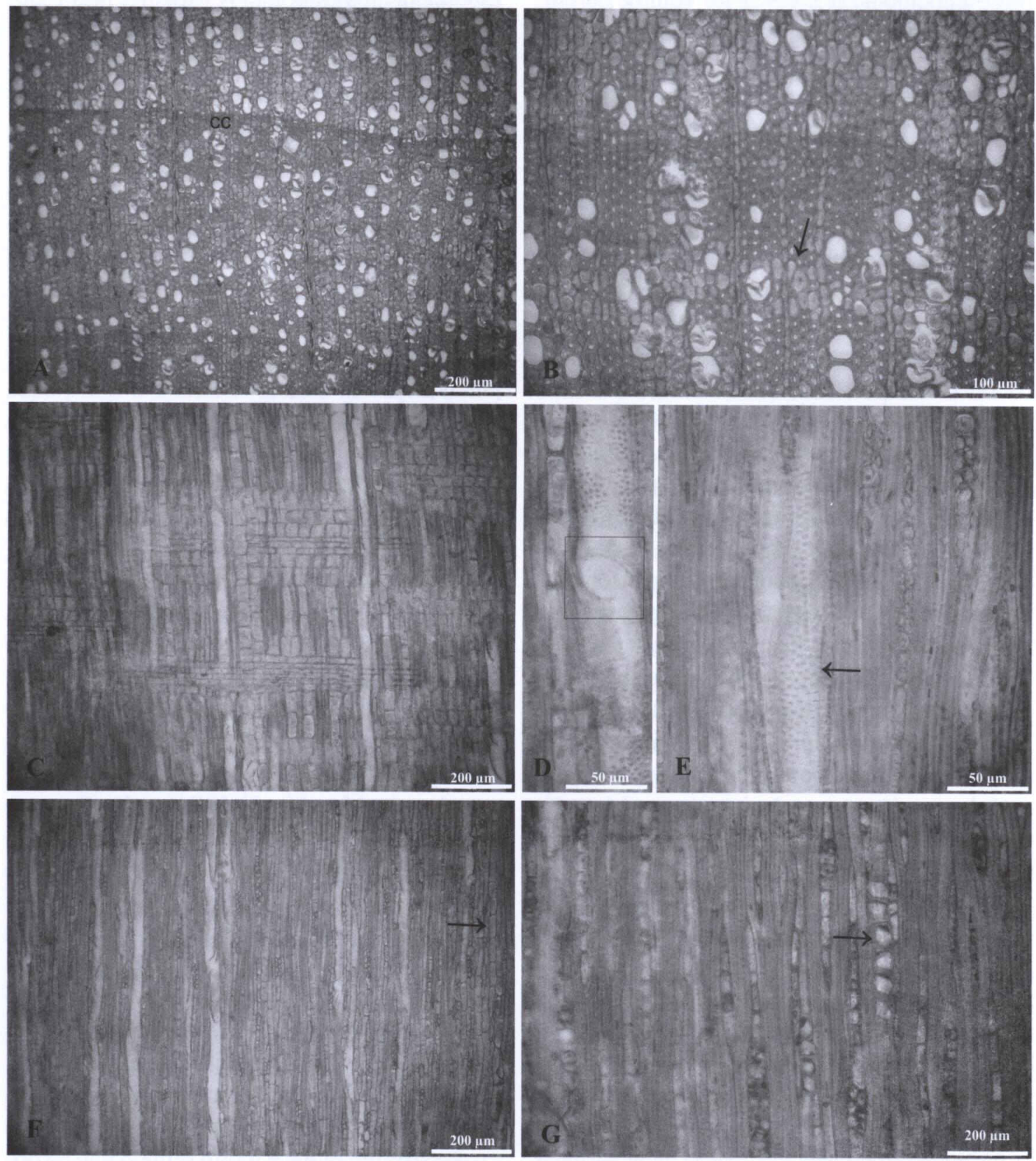

FIGURA 1 - Fotomicrografias da estrutura anatômica. A - Limite de anel de crescimento (cc), porosidade difusa, poros solitários e parênquima apotraqueal difuso-em-agregados, em seção transversal. B - Mesmo plano anatômico, destacando poros de seção poligonal, circular a oval, parênquima em linha tangencial (seta) e fibras de paredes finas até espessas. C - Raio heterogêneo, com células procumbentes no corpo multisseriado e células quadradas e eretas nas margens, visto em seção longitudinal radial. D - Mesmo plano anatômico, salientando placa de perfuração simples (quadrado). E - Vaso com pontoações intervasculares alternas (seta), em seção longitudinal tangencial. F - Raios estreitos e parênquima axial seriado (seta), em seção longitudinal tangencial. G - Detalhe de série parenquimática cristalífera (seta), raios uni e bisseriados e fibras com pontoações areoladas, em seção longitudinal tangencial. 
de até 6 células (Metcalfe \& Chalk, 1972). A presença de conteúdos, bem como sua abundância, podem, igualmente, ser valiosos para a identificação. Em Eugenia mansoi, a observação de escasso conteúdo em células radiais assemelha-se ao observado em E. uniflora e $E$. cerasiflora (Soffiatti \& Angyalossy-Alfonso, 1999); o caráter, todavia, não é referido para $E$. involucrata (Marchiori, 1984b). Cabe salientar que esta característica adquire maior importância no caso de espécies com conteúdo abundante, caso de Myrceugenia myrtoides (1987b), Calyptrantes concinna (Marchiori, 1997) e Campomanesia guazumaefolia (Marchiori, 1998).

A observação de pontoações areoladas em fibras de Eugenia mansoi contraria referência de Metcalfe \& Chalk (1972) para o gênero em questão; segundo estes autores, tanto em Eugenia, como em Gomidesia e Jambosa, ocorrem pontoações simples ou indistintamente areoladas. Marchiori (1984b) anota, igualmente, a presença de fibras libriformes na madeira de E. involucrata. Por outro lado, a observação de fibras com pontoações areoladas, por Soffiatti \& Angyalossy-Alfonso (1999), corrobora os resultados do presente estudo. Devido à variabilidade observada, a natureza das fibras cresce em importância na segregação de espécies em Eugenia.

Com relação às características quantitativas, os valores de elementos vasculares aproximamse aos referidos por Marchiori (1984b), com exceção da freqüência $\left(21 / \mathrm{mm}^{2}\right)$ e diâmetro $(58 \mu \mathrm{m})$ de poros, que ficaram abaixo e acima, respectivamente. Com relação aos resultados de Soffiatti \& Angyalossy-Alfonso (1999), apenas o diâmetro de poros referido pelas autoras $(42 \mu \mathrm{m})$ merece observação, por ser consideravelmente maior do que o presentemente observado. Cabe lembrar que características quantitativas, em especial de vasos, são muito influenciadas pelas condições do meio, devendo, portanto, serem tomadas com cautela. Na espécie em estudo, a frequiência de poros apresenta uma variação maior entre as amostras coletadas do que o verificado em outras espécies (inclusive de outros gêneros), listadas na bibliografia.

No tocante à altura das séries de parênquima axial, não se observa divergência com relação aos trabalhos anteriormente referidos, havendo, apenas, pequenas diferenças nos limites inferior e superior. Este fato reduz o valor taxonômico do caráter, ao menos para as espécies em que ocorre sobreposição. No caso dos raios, a tendência coincide com o observado no parênquima axial, com exceção da frequiência, pois, em valores médios, ultrapassa o referido por Marchiori (1984b) para Eugenia involucrata (16 raios/ $\mathrm{mm})$. Por sua vez, o comprimento de fibras $(989 \mu \mathrm{m})$ assemelha-se ao encontrado por Soffiatti \& Angyalossy-Alfonso (1999), ficando, todavia, um pouco abaixo do referido por Marchiori (1984b) para E. involucrata $(1226 \mu \mathrm{m})$; esta característica anatômica, bem como a freqüência de raios, pode ser útil para fins taxonômicos, no gênero em questão.

\section{REFERÊNCIAS BIBLIOGRÁFICAS}

BURGER, L. M., RICHTER, H. G. Anatomia da Madeira. São Paulo: Ed. Nobel, 1991. 154 p.

DUJARDIN, E. P. Eine neue Holz-Zellulosenfaerbung. Mikrokosmos, n. 53, p. 94, 1964.

IAWA COMMITTEE. IAWA list of microscopic features for hardwood identification. IAWA Bulletin., v.10, n. 3, p. 218-359, 1989.

MARCHIORI, J. N. C. Estudo anatômico do xilema secundário de algumas espécies dos gêneros Acacia e Mimosa, nativas no Estado do Rio Grande do Sul. 1980. 186f. Dissertação (Mestrado em Engenharia Florestal) - Universidade Federal do Paraná, Curitiba, 1980.

MARCHIORI, J. N. C. Anatomia descritiva da madeira do murtilho Myrrhinium loranthoides (Hook. et Arn.) Burret (Myrtaceae). Revista do Centro de Ciências Rurais, Santa Maria, v. 14, n. 1, p. 43-50, 1984a.

MARCHIORI, J. N. C. Anatomia da madeira de Eugenia involucrata DC. (Myrtaceae). Ciência e Natura, Santa Maria, v. 6, p. 127-136, 1984b. 
MARCHIORI, J. N. C. Anatomia descritiva do lenho de Feijoa sellowiana Berg. Ciência e Natura, Santa Maria, v. 6, p. 117-125, 1984c.

MARCHIORI, J. N. C. Estudo anatômico da madeira de Myrciaria tenella (DC.) Berg. Ciência e Natura, Santa Maria, v. 9, p. 87-95, 1987a.

MARCHIORI, J. N. C. Anatomia descritiva da madeira de Myrceugenia myrtoides Berg. Ciência e Natura, Santa Maria, v. 9, p. 113-120, 1987b.

MARCHIORI, J. N. C. Estudo anatômico da madeira de Myrceugenia glaucescens (Camb.) Legr. et Kaus. Ciência e Natura, Santa Maria, v. 10, p. 105-113, 1988.

MARCHIORI, J. N. C, BRUM, E. T. Anatomia da madeira do guamirim-facho, Calyptranthes concinna DC. (Myrtaceae). Ciência Rural, Santa Maria, v. 27, n. 2, p. 217-222, 1997.

MARCHIORI, J. N. C. Estudo anatômico da madeira de sete-capotes, Campomanesia guazumaefolia (Camb.) Berg. (Myrtaceae). Ciência Rural, Santa Maria, v. 28, n. 1, p. 47-51, 1998.

MARCHIORI, J. N. C., SOBRAL, M. Dendrologia das Angiospermas: Myrtales. Santa Maria: Editora UFSM, 1997.304 p.

MATTOS, J. R. Mirtáceas do Rio Grande do Sul. Roessléria, Porto Alegre, v. 6, n. 1, p. 201-205, 1984.
METCALFE, C. R., CHALK, L. Anatomy of the Dicotyledons. Oxford: Clarendon Press, 1972. 1500p.

RECORD, S. J., HESS R. W. Timbers of the New World. New Haven: Yale University Press, 1949. 640p.

ROTMAN, A. D. Myrtaceae, Mirtáceas. In: BURKART, A., BACIGALUPO, N. M. Flora Ilustrada de Entre Rios - Argentina. Buenos Aires: Colección científica del I.N.T.A., 2005. p. 472-500.

SANTANDER, C. A. B., GONZÁLEZ, I. A. G. Flora arbórea del Uruguay. Con énfasis en las especies de Rivera y Tacuarembó. Montevideo: COFUSA, 2007.544 p.

SOBRAL, M. A família Myrtaceae no Rio Grande do Sul. São Leopoldo: Editora Unisinos, 2003. p. 64-65.

SOFFIATTI, P., ALFONSO, V. A. Estudo anatômico comparativo do lenho e da casca de duas espécies de Eugenia L. (Myrtaceae). Revista Brasileira de Botânica, São Paulo, v. 22, n. 2, p. 175184, 1999.

VLIET, G. J. C. VAN, BAAS, P. Wood anatomy and classification of the Myrtales. Annals of the Missouri Botanical Garden, Saint Louis, n. 71, p. 783-800, 1984.

WIEDENBRUG, W. Maderas chilenas: contribución a su anatomía e identificación. Lilloa, Tucuman, n. 16, p. 263-375, 1948. 